\title{
Mandibular and mental foramen - A morphometric study in western Maharashtra
}

\author{
Anand Jagannath Reddy ${ }^{1}$, Rakhi Milind More ${ }^{2, *}$, Rajendra S. Garud ${ }^{3}$ \\ ${ }^{\mathbf{1}}$ Assistant Professor, Dept. of Anatomy, MIMSR Medical College, Latur, Maharashtra, ${ }^{\mathbf{2}}$ Associate Professor, Dept. of Anatomy, \\ K. J. Somaiya Medical College, Mumbai, Maharashtra, ${ }^{3}$ Professor and Head, Dept. of Anatomy, Bharati Vidyapeeth Deemed \\ University Medical College, Pune, Maharashtra, India
}

*Corresponding Author:

Email: drrakhimmore@gmail.com

Received: $17^{\text {th }}$ April, 2018

Accepted: $25^{\text {th }}$ April, 2018

\begin{abstract}
Mandible is the only movable bone of the facial skeleton that forms almost the lower half of the face. In ontogeny, the mandible undergoes substantial morphological and dimensional changes. These changes are largely associated with development of primary and secondary dentition in the human. ${ }^{1}$ The present study was undertaken to evaluate the anatomical features of mandible i.e. position of mental and mandibular foramina in western Maharashtra and to compare these findings with earlier studies. The findings of this study, variations in size, shape and relationships of dental and lower facial skeletal structure might be useful in providing important data to anatomists, archaeologists, forensic legal experts and maxillo-facial surgeons. Measurements were made on one hundred and ten dry, macerated adult human mandibles of unknown sex from western Maharashtra. Measurements of mental and mandibular foramen from various mandibular anatomical landmarks were taken. In present study it was observed that the most common position of mental foramen is in the line of long axis of 2nd premolar tooth which is universally accepted. Accessory mental foramen was found in one mandible located in line with anterior margin of 1 st molar.
\end{abstract}

Keywords: Mandible, Mental foramen, Mandibular foramen, Accessory mental foramen, Dentulous, Edentulous.

\section{Introduction}

Mandible is the only movable bone of the facial skeleton that forms almost the lower half of the face. It is one of the functionally and cosmetically important structures of the face that contributes to the facial contour.

Evolution of mandible, the lower jaw is of greatest interest in vertebrate history. It is one of the earliest innovations in the evolution of vertebrates. ${ }^{1}$ The present study was undertaken to evaluate the anatomical features of mandible i.e. the position of mental and mandibular foramina in western Maharashtra and to compare these findings with earlier studies. The influence of the state of dentition on mandibular symmetry was also studied. Mental foramen (MF) is an important anatomical landmark to facilitate surgical, local anaesthetic, and other invasive procedures for dental surgeons performing periapical surgery in the mental region of the mandible. MF gives passage to mental nerve, mental artery, and vein. ${ }^{2}$ Mandibular foramen is an irregular foramen located a little above the centre of the mandibular ramus on its medial surface. Inferior alveolar nerve and vessels pass through it, traverse the mandibular canal and supply the mandibular teeth. ${ }^{3}$ The findings of this study, variations in size, shape and relationships of dental and lower facial skeletal structure might be useful in providing important data to anatomists, implantologists, orthodontists, archaeologists, forensic legal experts and maxillo-facial surgeons.

\section{Aim}

To prepare morphometric database of human mandible using various parameters.

\section{Objectives}

1. To compare the findings of the present study of western Maharashtra with the available data.

2. To contribute to quantitative aspect of mandibular morphology, that will be useful in preventing neurovascular complications after invasive procedures on the lower jaw.

\section{Materials and Methods}

Material: Measurements were made on one hundred and ten dry, macerated adult human mandibles of unknown sex. All mandibles were obtained from Bharati Vidyapeeth Deemed University Medical College, Pune and other Medical Colleges in Maharashtra, with prior permission of the concerned authorities. The mandibles were apparently normal, without any structural deformity. Dentulous (teeth $\geq 14$; $\mathrm{n}=98$ ) and Edentulous (without any teeth; $\mathrm{n}=12$ ) mandibles were included for this study. Parameters were measured bilaterally wherever required.

Equipment's:

1. Geometrical Protractor with marking up to $180^{\circ}$

2. Digital Vernier Calliper with $0.01 \mathrm{~mm}$. precision

3. Measuring scale having marking up to $150 \mathrm{~mm}$

4. Flexible measuring tape

5. Marker Pen and Pencil

6. Plain white papers 


\section{Methods}

1. All the linear measurements were taken with the help of flexible measuring tape, scale and digital vernier calliper and noted in $\mathrm{mm}$.

2. All the angular parameters were measured by tracing outline of the mandible on plain white paper and were noted in degrees, with the help of Protractor.

3. Before measuring, the various anatomical landmarks were marked with the pencil.

a. Mental foramen (MF)

b. Mandibular foramen (MDF)

The parameters used are as follows:-

1. Measurements of mental foramen from various mandibular anatomical landmarks; (Fig. 1)

a. Distance between centre of mental foramen and the most superior point of alveolar border in vertical axis $(\mathrm{MF}-\mathrm{AB})$.

b. Distance between centre of mental foramen and mid-point of the posterior border of the ramus (MF-PB).

c. Distance between centre of mental foramen and the most inferior point of the lower border of body of mandible in vertical axis (MF - IB).

d. Distance between centre of mental foramen and mid-point of symphysis (MF-SM).

2. Measurements of mandibular foramen from various mandibular anatomical landmarks; (Fig. 2)

a. Distance between centre of mandibular foramina and mid-point of anterior border of ramus (MDF$\mathrm{AB})$.

b. Distance between centre of mandibular foramina and mid-point of posterior border of ramus (MDFPB).

c. Distance between centre of mandibular foramen and the most inferior point of the lower border of mandible in vertical axis (MDF- IB)

d. Distance between centre of mandibular foramina and the most inferior point of the mandibular notch in vertical axis (MDF-MN).

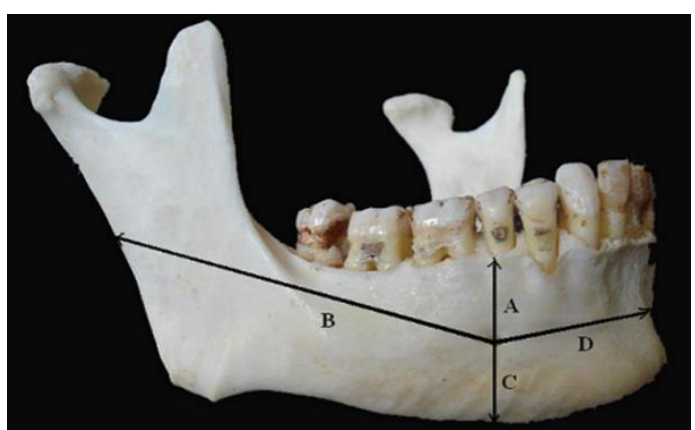

Fig. 1: A (MF-AB), B (MF-PB), C (MF-IB), D (MFSM)

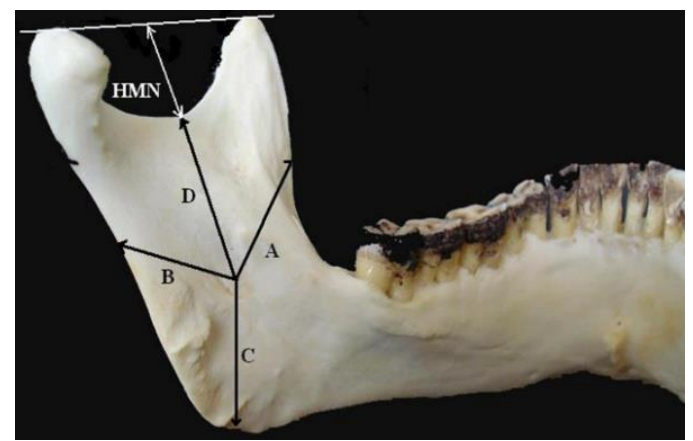

Fig. 2: A (MDF-AB), B (MDF-PB), C (MDF-IB), D (MDF-MN)

\section{Observations}

After completing the measurements of all the mandibles, data was arranged in the following groups:

1. Dentulous group $(\mathrm{n}=98)$.

2. Edentulous group $(\mathrm{n}=12)$.

Each parameter was studied by calculating Mean, Standard deviation (S.D.), ' $\mathrm{Z}$ ' value, and ' $\mathrm{P}$ ' value. Mean values of each parameter of right and left side in dentulous groups was analysed by applying $\mathrm{Z}$ test and in edentulous group by paired $\mathrm{t}-$ test.

Observations were noted as shown in the following tables 1-4 and bar diagram $1 \& 2$.

Table 1: Showing measurements (in mm) Mental Foramen (MF) of Right (R) and Left (L) from various anatomical landmark in Dentulous (D) group $n=98$

\begin{tabular}{|c|c|c|c|c|c|c|c|}
\hline & & Maximum & Minimum & Mean \pm SD & $\begin{array}{c}\text { Mean } \pm \text { SD } \\
(\mathrm{R}+\mathrm{L})\end{array}$ & $P$ value & $Z$ value \\
\hline \multirow{2}{*}{ MF-AB } & $\mathrm{R}$ & 22.99 & 5.43 & $13.95 \pm 2.80$ & \multirow{2}{*}{$13.69 \pm 2.42$} & \multirow{2}{*}{0.1325} & \multirow{2}{*}{1.5043} \\
\hline & $\mathrm{L}$ & 17.52 & 2.72 & $13.43 \pm 2.04$ & & & \\
\hline \multirow{2}{*}{ MF-PB } & $\mathrm{R}$ & 78.33 & 58.72 & $69.26 \pm 3.69$ & \multirow{2}{*}{$69.46 \pm 3.70$} & \multirow{2}{*}{0.5100} & \multirow{2}{*}{0.6588} \\
\hline & $\mathrm{L}$ & 80.43 & 58.72 & $69.66 \pm 3.71$ & & & \\
\hline \multirow{2}{*}{ MF-IB } & $\mathrm{R}$ & 16.27 & 9.80 & $12.69 \pm 1.37$ & \multirow{2}{*}{$12.75 \pm 1.49$} & \multirow{2}{*}{0.7293} & \multirow{2}{*}{0.3461} \\
\hline & $\mathrm{L}$ & 18.88 & 9.77 & $12.72 \pm 1.62$ & & & \\
\hline \multirow{2}{*}{ MF-SM } & $\mathrm{R}$ & 45.40 & 11.65 & $27.68 \pm 3.69$ & \multirow{2}{*}{$27.80 \pm 2.60$} & \multirow{2}{*}{0.6224} & \multirow{2}{*}{0.4924} \\
\hline & $\mathrm{L}$ & 31.33 & 11.83 & $27.91 \pm 1.52$ & & & \\
\hline
\end{tabular}

Table 1 shows that the difference in the distance between the alveolar border and mental foramen, posterior border and mental foramen, inferior border and mental foramen \& symphysis menti and mental foramen in dentulous mandibles on both sides is statistically insignificant. 
Table 2 : Showing measurements (in $\mathrm{mm}$ ) Mental Foramen (MF) of Right (R) and Left (L) from various anatomical landmark in Edentulous (ED) group n=12

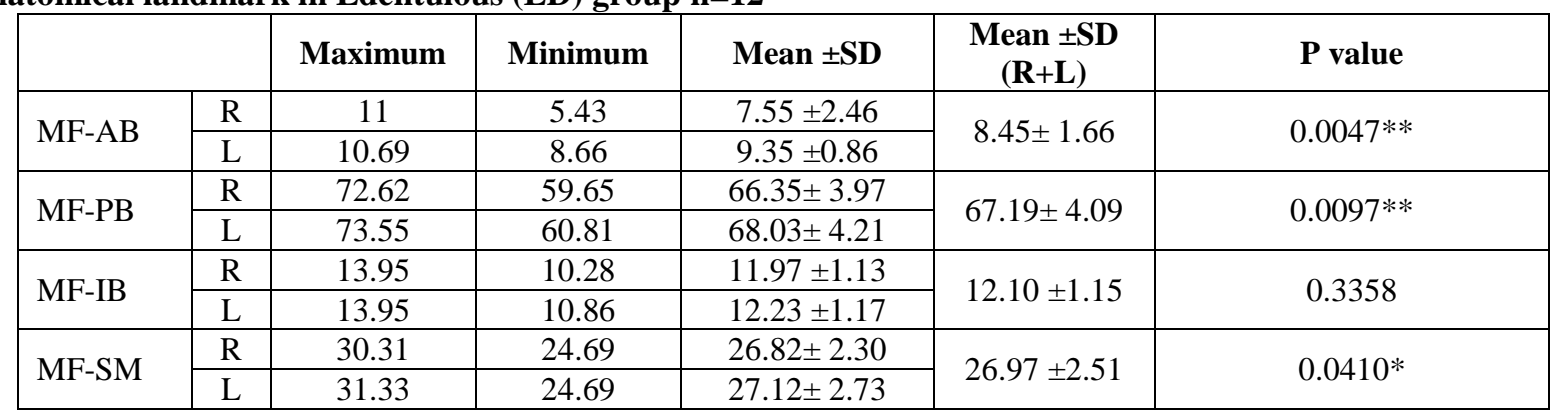

Statistically significant $*(\mathrm{P}<0.05)$, highly significant** $(\mathrm{P}<0.01)$

Abbreviations for Table $1 \&$ 2: AB-Alveolar border (MF-AB), PB-Posterior border of ramus (MF-PB), IB-Inferior border of mandible (MF-IB), SM-Symphysis menti (MF-SM)

Table 2 shows that the difference in the distance between the alveolar border and mental foramen, posterior border and mental foramen, \& symphysis menti and mental foramen in edentulous mandibles on both sides is statistically significant while the difference in the distance between inferior border and mental foramen statistically insignificant.

Table 3: Showing measurements (in $\mathrm{mm}$ ) of Mandibular Foramen (MDF) from various anatomical landmarks in dentulous group

\begin{tabular}{|c|c|c|c|c|c|c|c|}
\hline & & Maximum & Minimum & Mean \pm SD & $\begin{array}{c}\text { Mean } \pm \text { SD } \\
(\mathbf{R}+\mathrm{L})\end{array}$ & $P$ value & $Z$ value \\
\hline \multirow{2}{*}{ MDF-AB } & $\mathrm{R}$ & 23.29 & 9.71 & $17.34 \pm 2.69$ & \multirow{2}{*}{$17.49 \pm 2.78$} & \multirow{2}{*}{0.4423} & \multirow{2}{*}{0.7683} \\
\hline & $\mathrm{L}$ & 29.76 & 8.99 & $17.64 \pm 2.87$ & & & \\
\hline \multirow{2}{*}{ MDF-PB } & $\mathrm{R}$ & 19.38 & 9.87 & $15.08 \pm 1.88$ & \multirow{2}{*}{$14.94 \pm 1.88$} & \multirow{2}{*}{0.3253} & \multirow{2}{*}{0.9835} \\
\hline & $\mathrm{L}$ & 18.32 & 11.11 & $14.81 \pm 1.76$ & & & \\
\hline \multirow{2}{*}{ MDF-IB } & $\mathrm{R}$ & 36.22 & 14.98 & $25.56 \pm 4.33$ & \multirow{2}{*}{$25.44 \pm 4.27$} & \multirow{2}{*}{0.6863} & \multirow{2}{*}{0.4039} \\
\hline & $\mathrm{L}$ & 38.94 & 12.11 & $25.31 \pm 4.21$ & & & \\
\hline \multirow{2}{*}{ MDF-MN } & $\mathrm{R}$ & 39.45 & 15.86 & $24.03 \pm 6.83$ & \multirow{2}{*}{$23.99 \pm 6.73$} & \multirow{2}{*}{0.9290} & \multirow{2}{*}{0.0891} \\
\hline & $\mathrm{L}$ & 37.90 & 11.43 & $23.96 \pm 6.62$ & & & \\
\hline
\end{tabular}

Table 3 shows that the difference in the distance between the alveolar border and mandibular foramen, posterior border and mandibular foramen, inferior border and mandibular foramen, mandibular notch and mandibular foramen in dentulous mandibles on both sides is statistically insignificant.

Table 4: Showing measurements (in $\mathrm{mm}$ ) of Mandibular Foramen (MDF) from various anatomical landmarks in Edentulous (ED) group

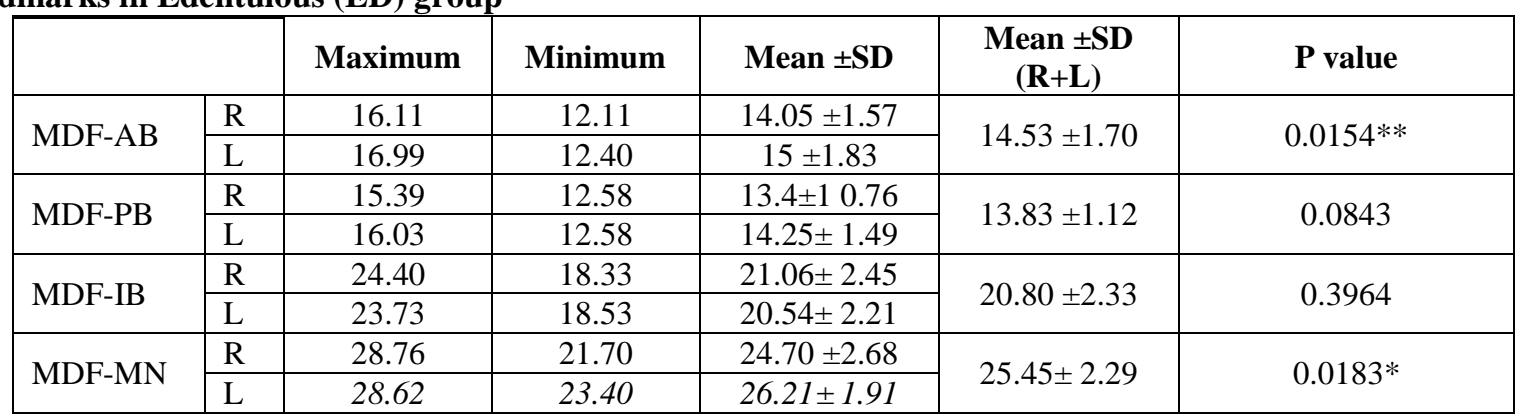

Statistically highly significant $* *(\mathrm{P}<0.01)$

Abbreviations for Table $3 \& 4$ : AB-Alveolar border (MDF-AB), PB-Posterior border of ramus (MDF-PB), IBInferior border of mandible (MDF-IB), MN-Mandibular notch (MDF-MN)

Table 4 shows that the difference in the distance between the alveolar border and mandibular foramen mandibular notch and mandibular foramen in edentulous mandibles on both sides is statistically significant. It also shows that the difference in the distance between the posterior border and mandibular foramen, inferior border and mandibular foramen edentulous mandibles on both sides is statistically insignificant. 
Bar diagram 1: Showing mental foramina measurements from the various anatomical landmarks

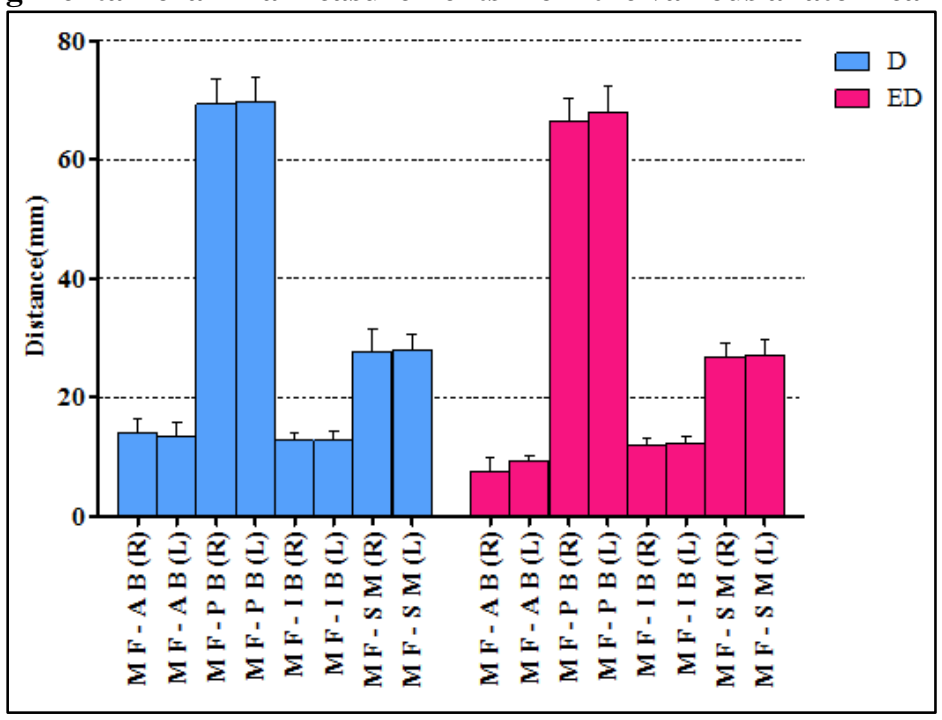

Bar diagram 2: Showing mandibular foramina measurements from the various anatomical landmarks

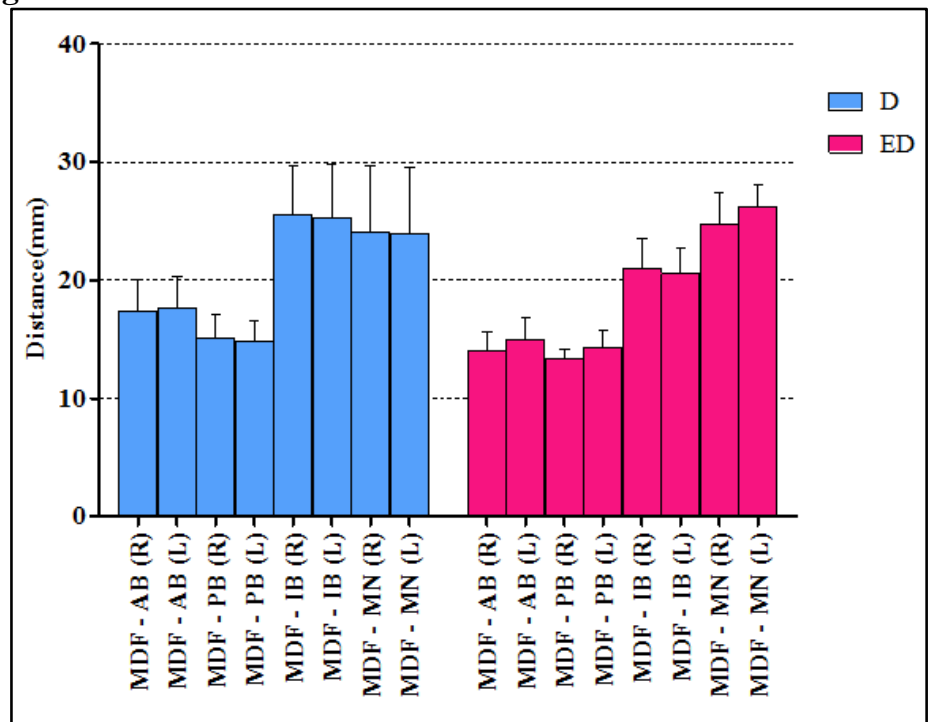

Abbreviations for Bar Diagrams 1 \& 2: AB-Alveolar border (MF-AB), PB-Posterior border of ramus (MF-PB), IBInferior border of mandible (MF-IB), SM-Symphysis menti (MF-SM), MN-Mandibular notch.

\section{Discussion}

Mandible presents a large number of parameters for morphometric study and has been widely studied over the last century. In the present study the parameters and their reference points are clearly defined and shown in the photographs. For comparison, we have selected database presented by those researchers who have selected similar reference points as in the present study. Majority of the studies done in different populations have focused their attention on sexual dimorphism. Some of the studies have been performed considering symmetry of the mandibles and have presented, compared values of right and left sides. In present study we have arranged our data in two groups i.e. dentulous and edentulous. We have compared the two parameters on right and left sides in these two groups.

A. In the present study mean values of distances of Mental Foramen (MF)

From Alveolar border (MF-AB) in

1. Dentulous group on right side is $13.95 \mathrm{~mm}$ (maximum $22.99 \mathrm{~mm}$, minimum $17.52 \mathrm{~mm}$ ) and on left side is 13.43 um $5.43 \mathrm{~mm}$, minimum $8.66 \mathrm{~mm}$ ) Statistically these two values are insignificant.

2. Edentulous group on right side is $7.55 \mathrm{~mm}$ (maximum $11 \mathrm{~mm}$, minimum $5.43 \mathrm{~mm}$ ) and on left side is $9.35 \mathrm{~mm}$ (maximum $10.69 \mathrm{~mm}$, minimum $2.72 \mathrm{~mm}$ ) statistically these two values are highly significant. $(\mathrm{P}<0.01)$ (Table 2)

From Posterior border (MF-PB) in 
1. Dentulous group on right side is $69.26 \mathrm{~mm}$ (maximum $78.33 \mathrm{~mm}$, minimum $58.72 \mathrm{~mm}$ ) and on left side is $69.66 \mathrm{~mm}$ (maximum $80.43 \mathrm{~mm}$, minimum $58.72 \mathrm{~mm}$ ) Statistically these two values are not significant.

2. Edentulous group on right side is $66.35 \mathrm{~mm}$ (maximum $72.62 \mathrm{~mm}$, minimum $59.65 \mathrm{~mm}$ ) and on left side is $68.03 \mathrm{~mm}$ (maximum $73.55 \mathrm{~mm}$, minimum $60.81 \mathrm{~mm}$ ) Statistically these two values are highly significant. $(\mathrm{P}<0.01)($ Table 4$)$

From Inferior border (MF-IB) in

1. Dentulous group on right side is $12.69 \mathrm{~mm}$ (maximum $16.27 \mathrm{~mm}$, minimum $9.80 \mathrm{~mm}$ ) and on left side is $12.72 \mathrm{~mm}$ (maximum $18.88 \mathrm{~mm}$, minimum $9.77 \mathrm{~mm}$ ) Statistically these two values are not significant.

2. Edentulous group on right side is $11.97 \mathrm{~mm}$ (maximum $13.95 \mathrm{~mm}$, minimum $10.28 \mathrm{~mm}$ ) and on left side is $12.23 \mathrm{~mm}$ (maximum $13.95 \mathrm{~mm}$, minimum $10.86 \mathrm{~mm}$ ) Statistically these two values are not significant.

From Symphysis Menti (MF-SM) in

1. Dentulous group on right side is $27.68 \mathrm{~mm}$ (maximum $45.40 \mathrm{~mm}$, minimum $31.33 \mathrm{~mm}$ ) and on left side is $27.91 \mathrm{~mm}$ (maximum $11.65 \mathrm{~mm}$, minimum $11.83 \mathrm{~mm}$ ) Statistically these two values are not significant.

2. Edentulous group on right side is $26.82 \mathrm{~mm}$ (maximum $30.31 \mathrm{~mm}$, minimum $24.69 \mathrm{~mm}$ ) and on left side is $27.12 \mathrm{~mm}$ (maximum $31.33 \mathrm{~mm}$, minimum $24.69 \mathrm{~mm}$ ) Statistically these two values are significant. $(\mathrm{P}<0.05)$ (Table 2)

Guillaume Captier et $\mathrm{al}^{4}$ found no difference between right and left side of distances of mental foramen in dentulous as well as edentulous group.

We compared the mean values of distances of mental foramen from the posterior \& inferior borders in dentulous mandibles with the available data. Mean value of distance from posterior border was $69.46 \mathrm{~mm}$ in our study, $68.85 \mathrm{~mm}$ (W. Apinh-asmit et al), ${ }^{5}$ $65.38 \mathrm{~mm}$ (LBL Prabhudha) ${ }^{6}$ \& $74.14 \mathrm{~mm}$ (Teen Meei wang et al). ${ }^{7}$ Mean value of distance from inferior border was $12.75 \mathrm{~mm}$ in our study, $14.88 \mathrm{~mm}$ (W. Apinh- asmit et al), $12.25 \mathrm{~mm}$ (LBL Prabhudha) \& 14.7 $\mathrm{mm}$ (Teen Meei wang et al).

1. The antero-posterior position of mental foramen was studied by many researchers. In the present study, we found the most common antero-posterior position in the line with the longitudinal axis of second mandibular premolar tooth (58.16\%). We compared our findings with the studies of other authors. Their findings were as follows Jennifer Neo in Indian population (Right $51 \%$, Left $43 \%$ ) in Malay population (Right $69.4 \%$, Left $66 \%$ ), ${ }^{8} \mathrm{Kim}$, In-Soo et al (64.3\%), ${ }^{9}$ LBL Prabhudha and BG Nanayakkara $(75 \%),{ }^{6} \mathrm{NM} \mathrm{Al}$ Jasser and $\mathrm{AL}$ Nwoku (45.3\%), ${ }^{10}$ Nazar Al Talabani et al (55\%), ${ }^{11}$ Oguz O and Bozkir MG $(61.76 \%),{ }^{12}$ Shankland
WE $2^{\text {nd }}(75.36 \%),{ }^{13}$ Teen - Meei Wang et al $(58.98 \%),{ }^{7} \mathrm{~W}$. Apinh-asmit et al $(69.98 \%),{ }^{5}$ Wei Cheong Ngeow and Yusof Yuzawati (69\%). ${ }^{14}$ In contrast, Moiseiwitsch JR, ${ }^{15}$ and Taiseer AlKhateeb et $\mathrm{al}^{16}$ observed the most common position of mental foramen in between mandibular premolar teeth which was the second most common position of mental foramen in the present study. In whites, Cutright $\mathrm{B}$ et $\mathrm{a}^{17}$ found most common position in between first and second premolar teeth; however, in Blacks he found posterior to second premolar.

2. In his study, Xie $\mathrm{Q}$ et $\mathrm{l}^{18}$ found the height of the basal bone below mental foramen was smaller in old edentulous women than in young and old dentate women. He attributed this to alveolar bone resorption in old edentulous women.

3. In the present study we found Accessory mental foramen (AMF) in one mandible (0.90\%) (Fig. 3), located in line with the 1st molar tooth. LBL Prabhodha ${ }^{6}(8.33 \%)$, Shankland WE $2^{\text {nd13 }}(6.62 \%)$ and $\mathrm{Toh} \mathrm{H}$ et al ${ }^{19}$ have also reported accessory mental foramina in their studies.

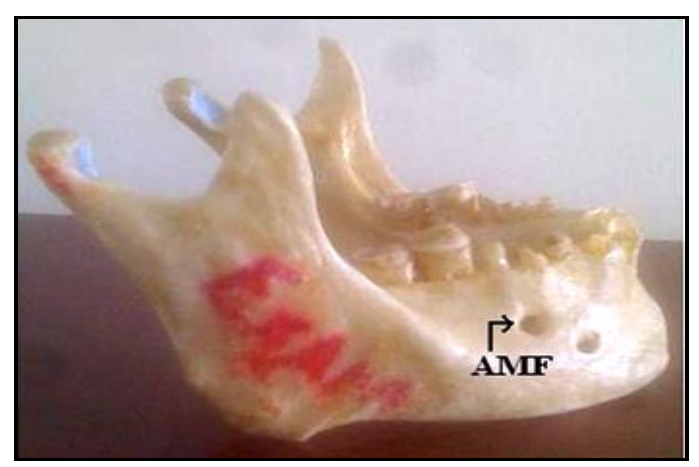

Fig. 3: AMF (Accessory mental Foramen)

B. In the present study mean values of distances of Mandibular Foramen (MDF)

From Anterior border (MDF-AB) in

1. Dentulous group on right side is $17.34 \mathrm{~mm}$ (maximum $23.29 \mathrm{~mm}$, minimum $9.71 \mathrm{~mm}$ ) and on left side is $17.64 \mathrm{~mm}$ (maximum $29.76 \mathrm{~mm}$, minimum $8.99 \mathrm{~mm}$ ) Statistically these two values are insignificant.

2. Edentulous group on right side is $14.05 \mathrm{~mm}$ (maximum $16.11 \mathrm{~mm}$, minimum $12.11 \mathrm{~mm}$ ) and on left side is $15 \mathrm{~mm}$ (maximum $16.99 \mathrm{~mm}$, minimum $12.40 \mathrm{~mm}$ ) statistically these two values are significant. $(\mathrm{P}<0.01)($ Table 4$)$

From Posterior border (MDF-PB) in

1. Dentulous group on right side is $15.08 \mathrm{~mm}$ (maximum $19.38 \mathrm{~mm}$, minimum $9.87 \mathrm{~mm}$ ) and on left side is $14.81 \mathrm{~mm}$ (maximum $18.32 \mathrm{~mm}$, minimum $11.11 \mathrm{~mm}$ ) statistically these two values are not significant.

2. Edentulous group on right side is $13.4 \mathrm{~mm}$ (maximum $15.39 \mathrm{~mm}$, minimum $12.58 \mathrm{~mm}$ ) and on left side is $14.25 \mathrm{~mm}$ (maximum $16.03 \mathrm{~mm}$, 
minimum $12.58 \mathrm{~mm}$ ) statistically these two values are not significant.

From Inferior border (MDF-IB) in

1. Dentulous group on right side is $25.56 \mathrm{~mm}$ (maximum $36.22 \mathrm{~mm}$, minimum $14.98 \mathrm{~mm}$ ) and on left side is $25.31 \mathrm{~mm}$ (maximum $38.94 \mathrm{~mm}$, minimum $12.11 \mathrm{~mm}$ ) statistically these two values are not significant.

2. Edentulous group on right side is $21.06 \mathrm{~mm}$ (maximum $24.40 \mathrm{~mm}$, minimum $18.33 \mathrm{~mm}$ ) and on left side is $20.54 \mathrm{~mm}$ (maximum $23.73 \mathrm{~mm}$, minimum $18.53 \mathrm{~mm}$ ) statistically these two values are not significant.

From Mandibular notch (MDF-MN) in

1. Dentulous group on right side is $24.03 \mathrm{~mm}$ (maximum $39.45 \mathrm{~mm}$, minimum $15.86 \mathrm{~mm}$ ) and on left side is $23.96 \mathrm{~mm}$ (maximum $37.90 \mathrm{~mm}$, minimum $11.43 \mathrm{~mm}$ ) statistically these two values are not significant.

2. Edentulous group on right side is $24.70 \mathrm{~mm}$ (maximum $28.76 \mathrm{~mm}$, minimum $21.70 \mathrm{~mm}$ ) and on left side is $26.21 \mathrm{~mm}$ (maximum $28.62 \mathrm{~mm}$, minimum $23.40 \mathrm{~mm}$ ) statistically these two values are significant. $(\mathrm{P}<0.01)$ (Table 4$)$.

3. The mean values of distances of mandibular foramen from mandibular notch on both right and left sides in dentulous group are less than in edentulous mandibles
We compared the mean values of distances of mandibular foramen from the posterior \& inferior borders in dentulous mandibles with the available data. Mean value of distance from posterior border was $14.94 \mathrm{~mm}$ in our study and $14.20 \mathrm{~mm}$ in a study conducted by A.C. Gabriel. ${ }^{20}$ Mean value of distance from inferior border was $25.44 \mathrm{~mm}$ in our study and $21.49 \mathrm{~mm}$ in a study conducted by A.C. Gabriel. ${ }^{20}$

4. A.C. Gabriel ${ }^{20}$ described correlation between mandibular foramen and breadth of ramus. $\mathrm{He}$ stated that more upright ramus, then the higher will be the mandibular foramen, the greater will be the distance of this foramen from the posterior border and broader will be the ramus.

5. Hayward $\mathbf{J}$ et $\mathrm{al}^{21}$ noted mean values of anterior dimension was greater than the mean values of the posterior dimension of the ramus and no appreciable difference was found in position of mandibular foramen on right and left side.

6. F.B. Prado et $\mathrm{al}^{22}$ observed statistically significant difference in position of mandibular foramina in dentate and edentate mandibles. In dentate mandibles measurements showed significant differences compared to the edentate mandibles except for MDF-MN. (Table 6). He concluded that the mandibular foramina position changes with loss of teeth and this variability may be responsible for occasional failure of inferior alveolar nerve block.

Table 5: Showing comparison of mean values of distances of Mental Foramen (MF) from anatomical landmarks in dentulous (D) \& edentulous groups with the study of Guillaume Captier

\begin{tabular}{|c|c|c|c|c|}
\hline 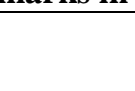 & & & Present study (mm) & $\begin{array}{c}\text { Guillaume Captier et al } \\
(\mathrm{mm})\end{array}$ \\
\hline \multirow{4}{*}{ MF-PB } & \multirow{2}{*}{$\mathrm{D}$} & $\mathrm{R}$ & 69.26 & 73.79 \\
\hline & & $\mathrm{L}$ & 69.66 & 74.02 \\
\hline & \multirow{2}{*}{$\mathrm{ED}$} & $\mathrm{R}$ & 66.35 & 73.93 \\
\hline & & $\mathrm{L}$ & 68.03 & $74.55 \mathrm{~s}$ \\
\hline \multirow{4}{*}{ MF-IB } & \multirow{2}{*}{$\mathrm{D}$} & $\mathrm{R}$ & 12.69 & 13.79 \\
\hline & & $\mathrm{L}$ & 12.72 & 13.75 \\
\hline & \multirow{2}{*}{ ED } & $\mathrm{R}$ & 11.97 & 13.45 \\
\hline & & $\mathrm{L}$ & 12.23 & 13.65 \\
\hline \multirow{4}{*}{ MF-SM } & \multirow{2}{*}{$\mathrm{D}$} & $\mathrm{R}$ & 27.68 & 25.96 \\
\hline & & $\mathrm{L}$ & 27.91 & 26.00 \\
\hline & \multirow{2}{*}{ ED } & $\mathrm{R}$ & 26.82 & 26.24 \\
\hline & & $\mathrm{L}$ & 27.12 & 26.29 \\
\hline
\end{tabular}

Table 6: Showing comparison of mean values of distances of Mandibular Foramen (MDF) in dentulous (D) and edentulous (ED) group with available data

\begin{tabular}{|c|c|c|c|c|c|}
\hline & & & Present Study $(\mathrm{mm})$ & $\begin{array}{l}\text { F.B. Prado } \\
\text { et al (mm) }\end{array}$ & $\begin{array}{c}\text { Guillaume } \\
\text { Captier et al } \\
(\mathrm{mm})\end{array}$ \\
\hline \multirow{4}{*}{ MDF-AB } & \multirow{2}{*}{$\mathrm{D}$} & $\mathrm{R}$ & 17.34 & 19.2 & - \\
\hline & & $\mathrm{L}$ & 17.64 & 18.8 & - \\
\hline & \multirow{2}{*}{ ED } & $\mathrm{R}$ & 14.05 & 17.5 & - \\
\hline & & $\mathrm{L}$ & 15 & 17.4 & - \\
\hline \multirow{2}{*}{ MDF-PB } & \multirow{2}{*}{ D } & $\mathrm{R}$ & 15.08 & 14.2 & 15.39 \\
\hline & & $\mathrm{L}$ & 14.81 & 13.9 & 15.41 \\
\hline
\end{tabular}




\begin{tabular}{|c|c|c|c|c|c|}
\hline & \multirow{2}{*}{ ED } & $\mathrm{R}$ & 13.4 & 12.8 & 14.90 \\
\hline & & $\mathrm{L}$ & 14.25 & 12.9 & 14.57 \\
\hline \multirow{4}{*}{ MDF-IB } & \multirow{2}{*}{ D } & $\mathrm{R}$ & 25.56 & 28.3 & - \\
\hline & & $\mathrm{L}$ & 25.31 & 28 & - \\
\hline & \multirow{2}{*}{ ED } & $\mathrm{R}$ & 21.06 & 26.4 & - \\
\hline & & $\mathrm{L}$ & 20.54 & 26.4 & - \\
\hline \multirow{4}{*}{ MDF-MN } & \multirow{2}{*}{ D } & $\mathrm{R}$ & 24.03 & 23.6 & 24.87 \\
\hline & & $\mathrm{L}$ & 23.96 & 23.1 & 23.86 \\
\hline & \multirow{2}{*}{ ED } & $\mathrm{R}$ & 24.70 & 23.4 & 24.67 \\
\hline & & $\mathrm{L}$ & 26.21 & 22.9 & 24.74 \\
\hline
\end{tabular}

\section{Conclusion}

1. In edentulous group symmetry of mandible was affected by absence of teeth.

2. Distance of mental foramen from alveolar border, posterior border and symphysis menti and distances of mandibular foramen from anterior border and mandibular notch were statistically significant,

3. Most common position of mental foramen in the line of long axis of 2 nd premolar tooth.

4. Accessory mental foramen was found in one mandible.

The present study involved the preparation of morphometric database of Human mandibles in Indian population which needs to be extended further to evaluate hidden parameter like mandibular body thickness which will be of great use to implantologists.

\section{References}

1. Jon Mallatt - Ventilation and the origin of jawed vertebrates: a new mouth. Zoological Journal of the Linnean Society (August 1996)117(4);329-404.

2. B Lalitha, Ephraim Vikram Rao, Morphology and Morphometry of Mental Foramen in Dry Adult South Indian Mandibles: A Cross-Sectional Study, International Journal of Scientific Study, June 2016, 4;(3):140-142.

3. Diana Laishram1, Deepti Shastri, Morphometric Analysis of Mandibular and Mental Foramen, Journal of Dental and Medical Sciences, Ver. V (Dec. 2015),14(12):82-86.

4. Guillaume Captier, Julien Lethuilier, Mohamed Oussaid, Francois Canovas, Francois Bonnel - Neural symmetry and functional asymmetry of the mandible; Surg Radiol Anat. (2006),28;(4)379-386.

5. W. Apinhasmit, D. Methathrathip, S. Chompoopong, S. Sangvichien - Mental foramen in Thais: an anatomical variation related to gender and side; Surg Radiol Anat. (October 2006), 28(5);529-533.

6. LBL Prabhudha, BG Nanayakkara - The position dimension and morphological variations of menatal foramen in mandibles; Galle Medical Journal (September 2006),11(1);13-15.

7. Teen-Meei Wang, Chung Shif, Jiang-Chuan Liu, KuenJia Kuo - A Clinical and Anatomical Study of the Location of the Mental Foramen in Adult Chinese Mandibles; Acta Anat. (1986),126(1):29-33.

8. Jennifer Neo - The position of the mental foramen in Singaporean Malyas and Indians; Anesth Prog. (1989),36(6):276-278.

9. Kim, In-Soo, Kim, Su-Gwan, Kim, Young-Kyun, Kim, Jae-Duk - Position of the Mental Foramen in a Korean
Population; A Clinical and Radiographic Study Implant Dentistry (December 2006), 15(4);404-411.

10. NM Al Jasser and AL Nwoku - Radiographic study of the mental foramen in a selected Saudi population; Dentomaxillofac Radiol. (1998)27(6);341-343.

11. Nazar Al Talabani, Ibrahim S. Gataa, Khalid Jaff Precise computer - based localization of the mental foramen on panoramic radiograph in a Kurdish population; Oral Radiol. (2008), 24(2):59-63.

12. Oguz O, Bozkir MG - Evaluation of location of mandibular and mental foramina in dry, young, adult human male, dentulous mandibles; West Indian Med J.(March 2002),51(1);14-16.

13. Shankland WE 2 nd. - The position of the mental foramen in Asian; Indians. J Oral Implantol. (1994), 20(2):118123.

14. Wei Cheong Ngeow and Yusof Yuzawati - The location of the mental foramen in a selected Malay population; Journal of Oral Science. (2003), 45(3):171-175.

15. Moiseiwitsch JR - Position of the mental foramen in a North American, white population; Oral Surg Oral Med Oral Pathol Oral Radiol Endod. (April 1998), 85(4):457460.

16. Taiseer Al-Khateeb, Abed Al-Hadi Hamasha, Khansa Taha Ababneh - Position of the mental foramen in a northern regional Jordanian Population; Surg Radiol Anat. (April 2007), 29(3):231-237.

17. Cutright B, Quillopa N, Schubert W - An anthropometric analysis of the key foramina for maxillofacial surgery; $J$ Oral Maxillofac Surg. (March 2003), 61(3);354-357.

18. Xie Q, Wolf J, Soikkonen K, Ainamo A - Height of mandibular basal bone in dentate and edentulous subjects Acta Odontol Scand. (December 1996), 54(6);379-383.

19. Toh H, Kodama J, Yanagisako M, Ohmori T Anatomical study of the accessory mental foramen and the distribution of its nerve; Okajimas Folia Anat Jpn (August 1992), 9(2-3):85-88.

20. A. C. Gabriel - Some anatomical features of mandible; $J$. Anat. (1958), 92(Pt 4):580-586.

21. Hayward J, Richardson ER, Malhotra SK - The mandibular foramen: its anteroposterior position; Oral Surg Oral Med Oral Pathol. (December 1977),44(6):837843.

22. F. B. Prado, F .C .Groppo, M. C. Volpato, P.H.F. Caria Morphological changes in the position of the mandibular foramen in dentate and edentate Brazilian subjecs; Clinical Anatomy. (2010), 23;(4):394-398.

How to cite this article Reddy AJ, More RM, Garud RS. Mandibular and mental foramen - A morphometric study in western Maharashtra. Ind J Clin Anat Physiol. 2018;5(3):366-372. 